\title{
Parasitological and PCR detection of Trypanosoma evansi in buffaloes from Luzon, Philippines
}

\author{
Waren N. Baticados*, Darlene L. Castro and Abigail M. Baticados \\ Department of Veterinary Paraclinical Sciences, College of Veterinary Medicine, University of the \\ Philippines,Los Baños, College Laguna, Philippines. \\ Accepted 02 November 2011
}

\begin{abstract}
The study investigated the occurrence of trypanosomosis in water buffaloes using parasitological and molecular methods. Buffaloes of different ages and both sexes comprising Bulgarian Murrah and some crosses were used in the study. Two of the 145 samples $(0.13 \%)$ were positive for Trypanosoma evansi in both, blood parasite examination and PCR. One female buffalo (1/54 samples; $1.86 \%)$ from a lactating herd in the city of Muñoz, Nueva Ecija (Region 3) and another (1/51 samples; 1.96\%) non-pregnant female belonging to caraheifer population from Los Baños, Laguna (Region 4) were found infected by $T$. evansi. The positive animals were in the age group of 3-4 years. Blood samples obtained from 40 buffaloes from Cagayan (Region 2) were found negative for trypanosome infection.
\end{abstract}

Key words: Bulgarian Murrah buffaloes, Surra, Laguna, Nueva Ecija

\section{INTRODUCTION}

In the Philippines and many other Asian countries, carabaos and other water buffaloes are significant sources of draft power, meat, milk and byproducts. The current population of the carabaos in the Philippine Island is about 3.075 million (Anonymous, 2011). Since these animals are found in tropical countries, they are continuously challenged by both internal and external parasites (Manuel, 1983).

Parasitism is one of the main limitations in carabao production in the Philippines (Manuel, 1983) and of major economic concern is trypanosomosis. There are several species of trypanosomes in livestock which include T. brucei, T. vivax, T. congolense and T. evansi (Soulsby, 1982; Nantulya, 1990; Sekoni et al., 2004). Except for T. evansi, none of the other species have been reported from the Philippines. However, because of animal importation into Philippines, the possibility of introducing other trypanosome species into the country cannot be discounted. Hence, it would be beneficial to establish the absence or presence of these species in the country. T. evansi, has been reported from all 13 regions of the Philippines, particularly Regions 2, 3 and 4 in Luzon, and Regions 9, 10 and 11 in Mindanao (Manuel, 1998). Trypanosoma evansi, the etiological agent of surra or locally known as "bayawak" or "higpit" (Baticados et al., 2011), infects numerous domestic and wild animals in warm climates (Connor, 1993 as cited in Guevarra,
1996). Cattle and water buffaloes are considered as reservoir hosts and the infection is subclinical in nature. However, outbreaks of acute disease may occur with sudden deaths (Soulsby, 1982). Trypanosomosis in cattle and buffaloes frequently causes marked suppression of the immune system leading to increased vulnerability to other opportunistic diseases such a pasteurellosis and anthrax (Stephen, 1986 as cited in Claes et al., 2004). Biting flies such as Tabanus, Stomoxys and Haematobia mechanically transmits the parasite (Soulsby, 1982; Levine, 1961).

Diagnosis of $T$. evansi infection or surra, specially in field populations of water buffaloes depends largely on blood parasite examination (BPE) through microscopic detection of the parasite in blood or tissue fluids of affected animals. However, the level of parasitemia is frequently low and fluctuating, specifically during the chronic stage, hence, the presence of the trypanosome can go undetected (Nantulya, 1990). Therefore, there is a need to use a more sensitive and specific technique.

The polymerase chain reaction (PCR) is a very sensitive and specific diagnostic tool and has been widely used in detecting trypanosomes in many countries, but it is not yet well utilized in the Philippines. There are very few locally conducted and published studies of surra detection using PCR (Baticados et al., 2011). At present, the availability of PCR technology is limited to selected universities and specialized government institutions. Its applicability in actual field studies

*Corresponding author's email: wnbaticados@uplb.edu.ph 
is of economic concern, especially its suitability as a diagnostic test in rural areas (Fernandez et al., 2010; Baticados et al., 2011). However, according to Beltran et al. (2004), trypanosome infection is often misdiagnosed due to low sensitivity and specificity of serological and parasitological tests. In addition, pathognomonic clinical and post mortem changes are lacking. Hence, there is a need to include PCR as part of the strategy to improve the reliability of diagnosis (Beltran et al., 2004). Thus, the objective of the study was to use PCR and BPE as diagnostic tools for trypanosomosis detection in water buffaloes in the Philippines. The occurrence of pathogenic trypanosome species other than $T$. evansi in the country was also investigated during the study.

\section{MATERIALS AND METHODS}

\section{Study Animals}

A total of 145 buffaloes of different ages and both sexes comprising Bulgarian Murrah and certain crosses, from a designated herd in selected regions of the island of Luzon, were used in the study (Fig. 1).The sample size was estimated using the formula of Thrusfield (1986).

\section{Collection and Examination of Blood}

Blood samples were collected from the jugular vein of each water buffalo using heparinized vacutainers. Giemsa-stained blood smears were microscopically examined under high power (40x) and oil immersion (100x).

\section{DNA Extraction}

The blood samples were processed for DNA extraction as reported by Baticados et al. (2005; 2004) and Sambrook and Russell (2001), with slight modifications. Briefly, one volume of sample was mixed with approximately nine volumes of DNA extraction buffer $(0.2 \mathrm{M} \mathrm{NaCl}$, $10 \mathrm{mM}$ Tris- $\mathrm{HCl} \mathrm{pH} 8.0,10 \mathrm{mM}$ EDTA $\mathrm{pH} 8.0$ and $1 \%$ SDS) and $1 / 10$ volume of proteinase $\mathrm{K}$ (Sigma-Aldrich, Inc., St. Louis, USA). The mixture was incubated at $55^{\circ} \mathrm{C}$ overnight. An equal volume of phenol-chloroform-isoamyl alcohol (PCI, pH 8.0) (Sigma-Aldrich, Inc., St. Louis, USA) was added and the sample was mixed vigorously using a vortex mixer. Samples were centrifuged at 15,513 g (Sigma 1-14, Sartorius AG, Germany) for $5 \mathrm{~min}$ at room temperature.

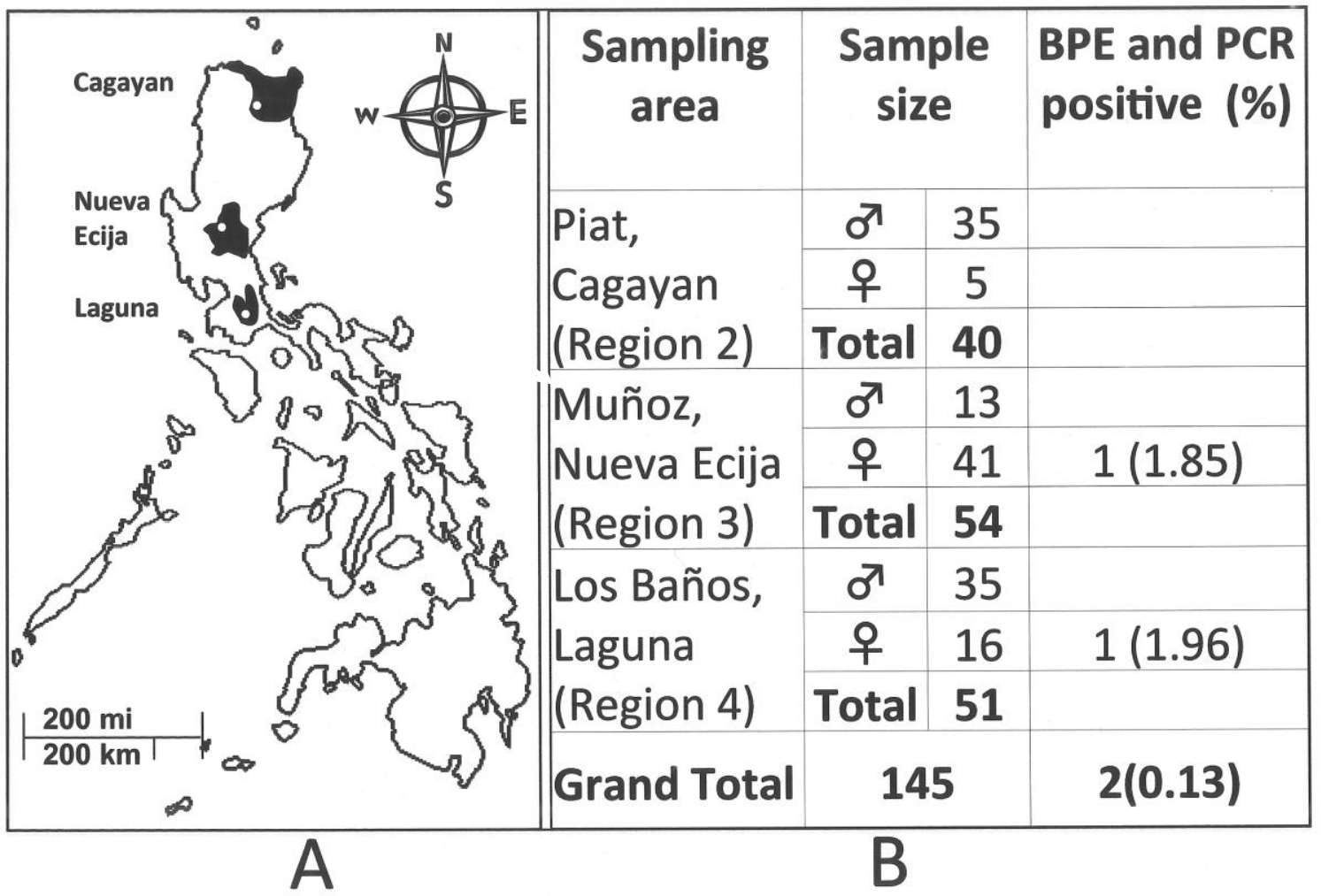

Figure 1. Sampling areas and sample size of buffaloes in Luzon, Philippines. A. Map of the Philippines showing the Provinces of Cagayan, Nueva Ecija and Laguna. (The white dots on the shaded areas represent the designated sampling sites) B. Number (\%) of sampled animals and BPE and PCR positive buffaloes. 
The upper aqueous phase was then transferred to a new microcentrifuge tube and mixed vigorously with approximately equal volumes of chloroform. The mixture was centrifuged at $15,513 \mathrm{~g}$ for $5 \mathrm{~min}$. The aqueous phase was again transferred to a new microcentrifuge tube and 1/10 volume of sodium acetate and $1 \mathrm{ml}$ ethanol $(99.5 \%)$ were added. After mixing, the processed samples were incubated for $1 \mathrm{~h}$ at freezing temperature and centrifuged at $15,513 \mathrm{~g}$ for $20 \mathrm{~min}$ at $4^{\circ} \mathrm{C}$. The supernatant was decanted and microcentrifuge tubes were refilled with $1 \mathrm{ml} 70 \%$ ethanol and processed as previously described. The supernatant was completely decanted, and the pellets air-dried and dissolved in 50 $\mu \mathrm{l}$ TE buffer (Tris-EDTA, $\mathrm{pH}$ $8.0)$ or triple distilled water.

\section{Polymerase Chain Reaction and Gel Electrophoresis Analysis}

Multiplex PCR was performed using primers (Invitrogen, Singapore) specific for T. evansi, T.vivax, T. brucei and T. congolense (Table 1) for preliminarily screening of DNA samples (Baticados et al., 2005; Viljoen et al., 2005; Njiruet al., 2004; Singh et al., 2004; Masiga et al. as cited in Morlaiset al., 1998). Initially, $2 \mu 1$ of template DNA was transferred into a PCR tube and $13 \mu 1$ of PCR mix [10x PCR buffer, $2 \mathrm{mM}$ dNTP mixture, triple distilled water, and $0.5 \mathrm{U}$ iTaq polymerase (iNTRON Biotechnology, Inc., Korea) and primers] were added into the sample. PCR was performed in a thermal cycler (Touchgene Gradient, TECHNE Cambridge, UK) programmed to a temperature-step cycle of $94^{\circ} \mathrm{C}$ at $10 \mathrm{~min}$, $94^{\circ} \mathrm{C}$ at $1 \mathrm{~min}, 60^{\circ} \mathrm{C}$ at $1 \mathrm{~min}$, followed by $2 \mathrm{~min}$ extension at $72^{\circ} \mathrm{C}$ for a total of 30 cycles. The final extension was carried out at $72^{\circ} \mathrm{C}$ for $7 \mathrm{~min}$. The PCR products were analyzed by electrophoresis in $1 \%$ TAE (Tris-acetate-EDTA) agarose gel together with 100 bp DNA ladder (Takara Bio Inc, Japan) as a standard molecular weight marker. Following ethidium bromide-staining (Sigma-Aldrich, Inc., St. Louis, USA), the gel was visualized by HoeferMacroVue UV-20 transillumination machine (Amersham Pharmacia Biotech, California, USA). After determining that the band size of the amplicon was comparable to $T$. evansi species, a confirmatory PCR assay composed of $2 \mu l$ template DNA and $18 \mu \mathrm{l}$ PCR mix containing only $T$. evansi species-specific primers (Table 1) was performed and processed as mentioned above. Subsequently, negative (distilled water) and positive (T. evansi and T. ansui) controls were included in the PCR run.

Table 1. Trypanosoma evansi species-specific primer pair and other species-specific primers.

\begin{tabular}{|c|c|c|c|c|}
\hline Specificity & Primer name & Primer Sequence & $\begin{array}{l}\text { Base } \\
\text { pairs }\end{array}$ & Reference \\
\hline \multirow[t]{2}{*}{ T. evansi } & PMURTTec.F & 5'-TGCAGACGACCTGACGCTACT-3' & 21 & Njiru et al., 2004 \\
\hline & PMURTTec.R & 5'-CTCCTAGAAGCTTCGGTGTCCT-3' & 22 & Singh et al., 2004 \\
\hline \multirow[t]{2}{*}{ T. congolense } & P74F & 5'-GGCAAACATTCTCGTTCG-3' & 18 & Baticados et al., 2005 \\
\hline & P74R & 5'-AGCACTACGAGCAAACATAC-3' & 20 & \\
\hline \multirow[t]{2}{*}{ T. brucei } & TBR1 & 5'-GAATATTAAACAATGCGCAG-3' & 20 & Morlais et al., 1998 \\
\hline & TBR2 & 5'-CGATTTATTAGCTTTGTTGC-3' & 20 & \\
\hline \multirow[t]{2}{*}{ T. vivax } & TVW1 & 5'-CTGAGTGCTCCATGTGCCAC-3' & 20 & Morlais et al., 1998 \\
\hline & TVW2 & 5'-CCACCAGAACACCAACCTGA-3' & 20 & \\
\hline
\end{tabular}




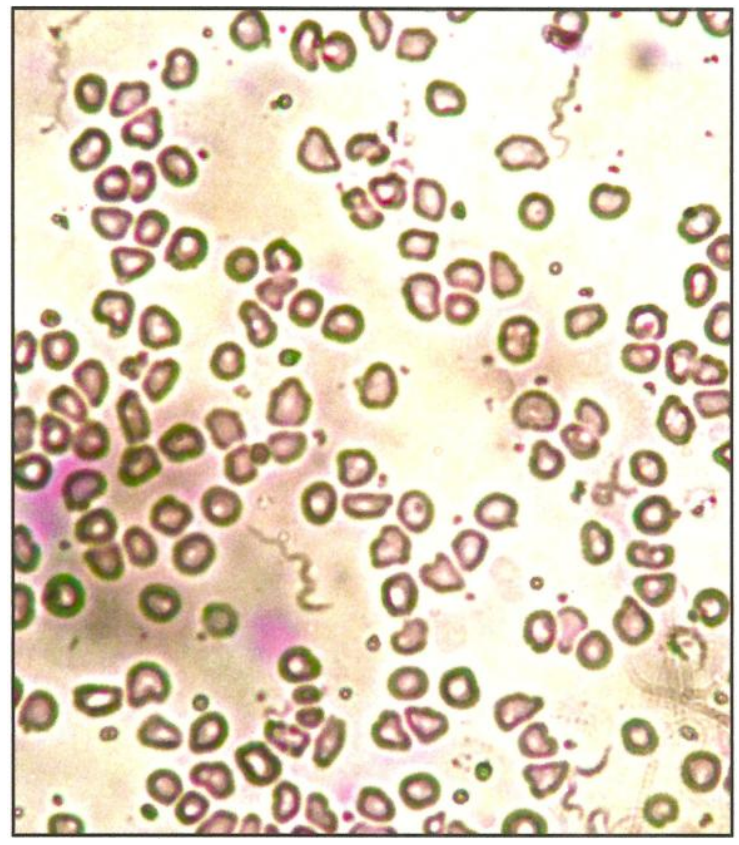

Figure 2. Haematozoic forms (400x) of Trypanosoma evansi seen in Giemsa-stained blood smear obtained from the infected water buffalo in Los Baños, Laguna.

\section{RESULTS}

In the sampled population of 145 water buffaloes, only two $(0.13 \%)$ were found positive for Trypanosoma evansi infection in both BPE method and PCR assay. Positive animals were found in Muñoz, Nueva Ecija (Region 3) (1.85 \%) and Los Baños, Laguna (Region 4) (1.96\%). None of the samples obtained from Piat, Cagayan (Region II) (Fig. 1) were positive.

Microscopic examination of blood smears showed the presence of Trypanosoma species with the characteristic morphology. About 3-6 organisms were found in each microscopic field, under high power objective (Fig. 2). The organism appeared leaf-like with a single flagellum under oil immersion. Their appearance was consistent with the descriptions of Soulsby (1982) for the genus Trypanosoma.

The PCR assay confirmed the parasite as $T$. evansi, the causative agent of surra. The amplicons displayed the specific $\sim 227$ base pair (bp) band, comparable to the positive control of $T$. evansi. The PCR band sizes specific for T. brucei (164 $\mathrm{bp}), T$. congolense (499 bp), and T. vivax (150 bp) (Baticados et al., 2005; Morlaiset al., 1998) were not detected after agarose gel electrophoresis of the PCR products. The results also confirmed that there was no mixed infection and that other livestock trypanosomes were not present in the water buffaloes sampled.

\section{DISCUSSION}

PCR is known to possess high sensitivity in terms of parasite detection (Masake et al., 2002; Mugittu et al., 2001; Solano et al., 1999). However, in early infections, parasitological and PCR techniques may show very comparable sensitivity (80\%). Conversely, during the chronic phase of infection, parasitological examination exhibits very low sensitivity $(<10 \%)$, whereas PCR is $2-3$ times more sensitive (20-30\%) (Desquesnes and Davila, 2002). In this study, it is likely that the two animals detected positive for parasites were in the active phase of infection. Therefore, enough parasites were circulating in the blood that allowed their detection in both blood smear examination and PCR assay. The infected animals were found to be female buffaloes that belonged to the age groups of $>3$ years (in Los Baños, Laguna) and 3-4 years (in Muñoz, Nueva Ecija). The infected buffalo from Los Baños was non-pregnant and belonged to the caraheifer population, while that of Muñoz buffalo came from the lactating herd. An investigation by Cheah et al. (1999) showed that the prevalence of parasitemia was highest in lactating animals. This was followed in descending order by the dry herd, late pregnant animals, early pregnant animals, calves and heifers. The plausible explanation for the higher prevalence of parasitemia in cows, as compared to heifers and calves, was attributed to the stress brought about by pregnancy and lactation. Therefore, it is likely that the positive animal from Muñoz was predisposed to infection due to lactation stress. On the other hand, infection in the buffalo from Los Baños may have been caused by other unknown factors.

The very low prevalence of infection in the buffalo herds examined could be due to several factors. Treatment of the herd with trypanocidal drugs may have rendered the animals negative for infection. Based on the history, animals had been treated with Isometamidium Chloride (Trypamidium- Suramin (), a trypanocidal drug. According to Desquesnes (2004) when the parasite dies, the persistence of free DNA in the circulation of the host is short-term ie. lasts only for 1-2 days. Furthermore, parasitemia may rise and fall substantially ranging from $>10^{6}$ parasites $/ \mathrm{ml}$ of blood (1000 parasites/ $\mu \mathrm{l})$, to $<1$ parasite/l of blood (0.000001 parasite/ $\mu \mathrm{l})$, which may also affect the sensitivity threshold of PCR. Trypanosome detection by PCR has a sensitivity threshold, which usually ranges from 1 to 20 parasites $/ \mathrm{ml}$ of 
blood (0.001-0.02 parasites/ $\mu \mathrm{l})$. If parasitemia is lower than this level, PCR cannot detect the infection (Desquesnes and Davila, 2002).

Moreover, problems with PCR reagents may also contribute to negative PCR results (Reifenberg et al., 1997). However, failure of one or more of the PCR reagents or sample contamination can readily be validated with a negative and positive control in each PCR run. Consequently, in this study, T. evansi positive and negative controls displayed the expected results after PCR amplification. Hence, the possibility that any of the PCR reagents failed was eliminated.

Even if only one animal positive for T. evansi was detected in both Muñoz and Los Baños areas, the possibility that the other herds may be infected cannot be eliminated, especially in the presence of the vector host. The feeding duration of Tabanus can be as short as $5 \mathrm{sec}$ and this duration is sufficient for the insect to acquire the infection. More significantly, an equally short contact period by an infected vector with an uninfected host is enough to infect the animal (Luckins, 1988). The adults have a flight range of $50 \mathrm{~km}$ (Luckins, 1988) so there is also a likelihood that the disease can be transmitted to nearby localities. Therefore, it would be beneficial to test water buffaloes in nearby areas of the same region

In summary, a total of two samples (2/145; $0.13 \%$ ) were positive for $T$. evansi in both BPE and PCR test. All infected animals were females of 3-4 years old. The confirmed positive animals originated from Region 3 (Muñoz, Nueva Ecija) and Region 4 (Los Baños, Laguna). The low level of detection could be attributed to trypanocidal drug treatment of the herd. Blood samples from 40 animals obtained from Piat, Cagayan (Region II) were found negative for trypanosome infection. The current data was able to provide molecular and parasitological evidence of the presence of $T$. evansi in carabaos from Regions 3 and 4 . Similarly, the results established that the detection of trypanosome by BPE and PCR assay were in agreement. In this regard, the PCR detection test must be viewed as an additional method for the effective monitoring and surveillance of the parasite and should be used side-by-side with the classical blood parasite examination method, which is widely used for routine diagnosis in the countryside. The results also indicated that there were no mixed infections and other livestock trypanosomes species in water buffaloes in the Philippines. The fact that a few (2) treated animals is still positive for haematozoic stages imply that the parasite had started to mount resistance against the drugs being used. Lastly, the results also suggest that drug treatment can be one of the reasons for low PCR detection in a herd.

\section{ACKNOWLEDGEMENTS}

The authors are indebted to the late Dr. Crisante M. Cristobal, Dr. Billy P. Divina and the Philippine Carabao Center officials and staff; Dr. Arnel del Barrio, Dr. Franklin Relin, Dr. Nancy Abes, Dr. Rommel Herrera, Dr. Chat Gutierrez, Dr. Lester Verona, Dr. Noel Marzan and Dr. Rovina Piñera, for their support and cooperation during sample collection.

\section{REFERENCES}

Anonymous (2011). Selected Statistics on Agriculture 2011. In:Proceedings of Bureau of Agricultural Statistics (BAS). Department of Agriculture, Bureau of Animal Industry, Eliptical Road, Quezon City, Manila, Philippines. Pp. 22.

Baticados, W.N., Fernandez, C.P., and Baticados, A.M. (2011). Molecular Detection of Trypanosoma evansi in Cattle from Quirino Province, Philippines. Veterinarski Arhiv. 81(5):635-646.

Baticados, W.N., Witola, W.H., Inoue, N., Kim, J.Y., Kuboki, N., Xuan, X., Yokoyama, N. and Sugimoto, C. (2005). Expression of a gene encoding Trypanosoma congolense putative Abc1 family protein as developmentally regulated. Journal of Veterinary Medicine Science 67:157-164.

Baticados, W.N. (2004). Studies on Application of Double-stranded RNA Interference on Functional Genomics of African Trypanosomes. Ph.D. Dissertation. The United Graduate School of Veterinary Sciences, Gifu University, Japan, Pp. 38-39.

Beltran, M.A., Copeman, B., Copland, R. and Reid, S. (2004). PCR-ELISA For Detection of Trypanosoma evansi in tissues in Buffaloes. Proceedings of $7^{\text {th }}$ World Buffalo Congress, Makati City, Philippines, Pp.89-90.

Cheah, T.S., Sani, R.A., Chandrawathani, P., Bahri, S. and Dahlan, I. (1999).Epidemiology of Trypanosoma evansi Infection in Crossbred Dairy Cattle in Malaysia.Tropical Animal Health and Production 31:25-31.

Cleas, F., Radwanska, M., Urakawa, T., Majiwa, P.A.O., Goddeeris, B. and Büscher, P. (2004).Variable surface glycoprotein RoTat 1.2 PCR as a specific diagnostic tool for the detection of Trypanosoma evansi infections. Kinetoplastid Biology and Disease 3:3.

Desquesnes, M. (2004). Livestock Trypanosomes and their Vectors in Latin America. OIE World Organization for Animal Health, Pp 78-133. 
Desquesnes, M. and Davila, A.M.R. (2002). Applications of PCR-based tools for detection and identification of animal trypanosomes: a review and perspectives. Veterinary Parasitology 109:213-231.

Fernandez, C.P., Baticados, W.N., and Baticados, A.M. (2010). Parasitological Examination for Trypanosoma theileri infection of cattle from Quirino Province, Philippines.Veterinary Medicine: Research and Report 1: 3-6.

Guevarra, F.Z. (1996). A subclinical case of trypanosomiasis in a four-year old male carabao.Case Report. College of Veterinary Medicine, University of the Philippines, Los Baños Laguna, Pp. 2.

Levine, N.D. (1961). Protozoan Parasites of Domestic Animals and Man. Burgess Publishing Company, Pp 43-58.

Luckins, A.G. (1988). Trypanosoma evansi in Asia. Parasitology Today 4: 137-141.

Manuel, M.F. (1983). Parasitic Diseases of Water buffaloes (Bubalis bubalis). Philippine Journal of Veterinary Medicine 22:108-125.

Manuel, M.F. (1998). Sporadic Outbreaks of Surra in the Philippines and its Economic Impact. Journal of Protozoological Research 8:131-138.

Masake, R.A., Njuguna, J.T., Brown, C.C. and Majiwa, P.A.O. (2002). The application of PCRELISA to the detection of Trypanosoma brucei and $T$. vivax infections in livestock. Veterinary Parasitology 105:179-189.

Morlais, I., Grebaut, P., Bodo, J.M., Djoha, S., Cuny, G., Herder, S. (1998). Detection and identification of trypanosomes be polymerase chain reaction in wild tsetse flies in Cameroon. Acta Tropica 70:109-117.

Mugittu, K.N., Silayo, R.S., Majiwa, P.A.O., Kimbita, E.K., Mutayoba, B.M. and Maselle. R. (2001). Application of PCR and DNA probes in the characterization of trypanosomes in the blood of cattle in Morogoro, Tanzania. Veterinary Parasitology 94:177-189.

Nantulya, V.M. (1990). Trypanosomiasis in domestic animals: the problems of diagnosis. Review Science Technique Office International Epizooties 9: 357-367.
Njiru, Z.K., Constantine, C.C., Ndung, J.M., Robertson, I., Okaye, S., Thompson, R.C.A. and Reid, S.A. (2004). Detection of Trypanosoma evansi in camels using PCR and CATT/T. evansi tests in Kenya.Veterinary Parasitology 124:187199.

Reifenberg, J.M., Solano, P., Duvallet, G., Cuisance, D., Simpore, J. and Cuny, G. (1997). Molecular characterization of trypanosome isolates from naturally infected domestic animals in Burkina Faso. Veterinary Parasitology71: 251-262.

Sambrook, J, and Russell, D.W. (2001). Molecular Cloning A Laboratory Manual. 3rd Edition Vol 2. Cold Spring Harbor Laboratory Press, Pp. 8.48.6, 8.18-8.23

Sekoni, V.O., Rekwot, P.I. and Bawa, E.K. (2004) Effects of Trypanosoma vivax and Trypanosoma congolense infections on the reaction time and semen characteristics of Zebu (bunaji) $x$ Friesian crossbred bulls. Theriogenology 61:55-62.

Singh, N., Pathak, K.M.L. and Kumar, R. (2004) A comparative evaluation of parasitological, serological and DNA amplification methods for diagnosis of natural Trypanosoma evansi infection in camels. Veterinary Parasitology 126:365-373.

Solano, P., Michel, J.F., Lefrancois, T., de La Rocque, S., Sidibe, I., Zoungrana, A. and Cuisance, D. (1999). Polymerase chain reaction as diagnosis tool for detecting trypanosomes in naturally infected cattle in Burkina Faso. Veterinary Parasitology 86:95-103.

Soulsby, E.J.L. (1982). Helminths, Arthropods, and Protozoa of Domesticated Animals. $7^{\text {th }}$ Edition Lea and Febiger. London. Pp. 532-33.

Thrusfield, M. (1986). Veterinary Epidemiology. Butterworth and Co. (Publishers) Ltd,U.K. Pp. 154-155.

Viljoen, G.J., Nel, L.H. and Crowther, J.R. (2005). Molecular Diagnostic PCR Handbook. Springer, Netherlands. Pp. 4, 53. 